\title{
(x) 111\|\|\|\|$M$ \\ Activation of SOD-3 is involved in the antioxidant effect of a new class of $\beta$-aryl-chalcogenium azide compounds in Caenorhabditis elegans
}

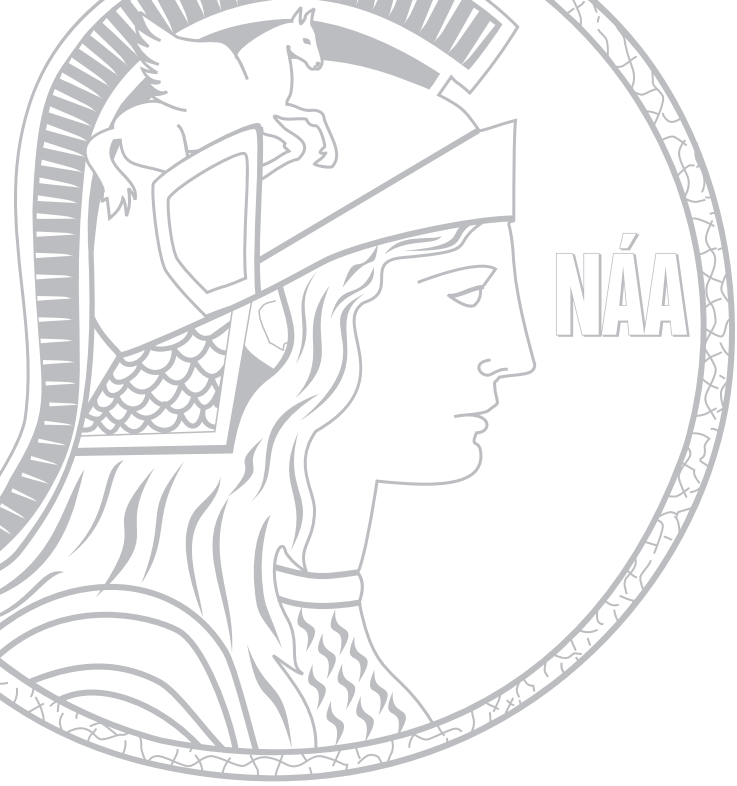

\author{
HODARA S. MOTTA, DANIEL ROOS, GREICE TABARELL, OSCAR E.D. RODRIGUES, \\ DAIANA ÁVILA \& CAROLINE B. QUINES
}

\begin{abstract}
Organic selenium, tellurium and sulfur compounds have been studied due to their pharmacological properties. For instance, the $\beta$-aryl-chalcogenium azide compounds have demonstrated antitumoral action in vitro. However, yet no pharmacological actions of this class of compounds were determined in vivo. Caenorhabditis elegans is a nematode that presents innumerable advantages in relation to mammalian models, such as having a small and transparent body, which allows the visualization of its internal anatomy, besides short life and low cost. Based on that, the aim of this work was to investigate the pharmacological and toxicological properties of $\beta$-aryl-chalcogenium azide compounds in C. elegans. As well, to evaluate the capacity of organochalcogenium compounds to repair oxidative damage induced by hydrogen peroxide and the possible mechanism of action of these compounds using CF1553 transgenic strain with superoxide dismutase (SOD-3) tagged with GFP. Our results showed that $\beta$-aryl-chalcogenium azide have low toxicity in wild-type worms and the pre-treatment protected against the damage induced by hydrogen peroxide at higher tested concentration. Associated with this, we observed that this protection is due in part to the increased expression of the antioxidant enzyme SOD-3. In conclusion, $\beta$-arylchalcogenium azide compounds caused low toxicity and induced stress-resistance by modulating SOD-3 expression in C. elegans.
\end{abstract}

Key words: organochalcogenides, selenium, C. elegans, oxidative stress, superoxide dismutase.

\section{INTRODUCTION}

Oxidative stress is the main factor for the etiology of various diseases and occurs when there is an imbalance between the production of reactive oxygen species and the antioxidant defense system (Poprac et al. 2017). The excess of ROS can damage important cellular macromolecules such as lipids, proteins and DNA and deregulate the activities of important enzymes involved in cell homeostasis (Poprac et al. 2017, Azadmanesh \& Borgstahl 2018).
The antioxidant defense system can be divided according to its origin and may be from an endogenous or exogenous nature. Glutathione peroxidase, catalase (CAT), superoxide dismutase (SOD) and thyroxine reductase (TrxR) are examples of endogenous enzymatic antioxidants sources (Poprac et al. 2017, Azadmanesh \& Borgstahl 2018). SODs perform their bio-protective role by converting superoxide into molecular oxygen and hydrogen peroxide by cyclic redox reactions containing a metal (Mn, Zn, Cu or Fe) at the active site, and for this reason it is considered a molecular drug 
target (Azadmanesh \& Borgstahl 2018, Bonetta 2017). The expression of these enzymes can be modulated by xenobiotics, and our group has been focused on investigating the molecular targets of molecules named organochalcogens (Wollenhaupt et al. 2014, Avila et al. 2012, Salgueiro et al. 2017, Soares et al. 2019).

The organochalcogen compounds present an atom of selenium, tellurium or sulfur in their chemical structure. They are promising pharmacological agents that have significant biological activities and may exhibit antiinflammatory, antioxidant, antinociceptive and neuroprotective properties (Chagas et al. 2017, Quines et al. 2014, Nogueira et al. 2004). Therefore, organoselenium and organotellurium compounds are promising pharmacological agents known to have a wide range of biological effects (Nogueira et al. 2004, Tiekink 2012).

However, several new organochalcogen compounds are synthetized every day and demand a rapid and efficient screening to evaluate their possible biological effects. Among them are $\beta$-aryl-chalcogenium azide compounds. These molecules have been evaluated in vitro for antitumoral effect on lung carcinoma A549 and for antioxidant properties, but no pharmacological actions were determined in vivo (Tabarelli et al. 2017). In this context, alternative animal models have been gaining attention in the attempt to reduce the number of mammals used in experimentation and also to reduce costs. Among these and due to the advantages, we have chosen the nematode Caenorhabditis elegans (C. elegans). Based on that, the aim of this study was to investigate the safety of four $\beta$-aryl-chalcogenium azide compounds in C. elegans, as well as to evaluate their capacity to repair oxidative damage induced by pro-oxidant agents and their possible mechanism of action by making use of a transgenic strain.

\section{MATERIALS AND METHODS}

\section{Chemical}

The compounds were synthesized according to the methods already described in the literature (Tabarelli et al. 2017). Briefly, to synthesize the $\beta$-aryl-chalcogenium azides we need $\beta$-chalcogenium amine compounds 4 (Scheme 1).

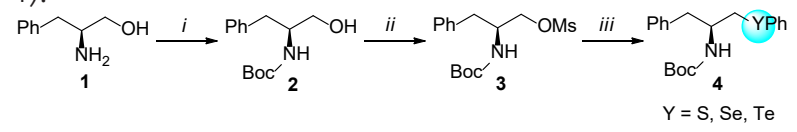

Scheme 1. Synthesis of chiral (Miyashita et al. 1988). [a] Reagents and conditions: (i) $\mathrm{BOC}_{2} \mathrm{O}, \mathrm{CH}_{3} \mathrm{CN}, \mathrm{rt}, 4 \mathrm{~h}$; (ii) MsCl, NEt 3 , THF, 0 8C, 30 min. (iii) PhYYPh/ $\mathrm{NaBH}_{4}, \mathrm{THF} / \mathrm{EtOH}$ (3:1), room temperature, $24 \mathrm{~h}$.

Compounds 4 were prepared from the corresponding commercially available $\alpha$-amino alcohols phenylalaninol 1. These compounds were quantitatively converted into the $\mathrm{N}$-Bocprotected aminoalcohols 2 by reaction with di-tert-butyl dicarbonate in acetonitrile. Thereafter, the alcohol mesylation was performed from the NBoc amino alcohol 2 using mesyl chloride in THF in the presence of $\mathrm{Et}_{3} \mathrm{~N}$. The introduction of the organochalcogenium moiety in the $\beta$-aminomesylates backbone 3 was performed employing a common methodology which is used for the introduction of organochalcogenium in alkylic substrates via generation of organochalcogenolates through the reaction of aryl dichalcogenides with $\mathrm{NaBH}_{4}$ in a mixture of THF and ethanol (Miyashita et al. 1988, Andreadou et al. 1996, Goodman \& Detty 2004).

The intermediates $\beta$-aryl-chalcogenium amines 5 were obtained via deprotection of the $\mathrm{N}$-Boc group from compounds 4 with trifluoracetic acid. The reaction was monitored by TLC and after completion and removal of the residual acid, the respective amines were directly reacted via diazotransference with triflyl 
azide $\left(\mathrm{TfN}_{3}\right.$ ) as a diazo donor group (Yan et al. 2005) obtaining the $\beta$-aryl-chalcogenium azides 6, scheme 2.

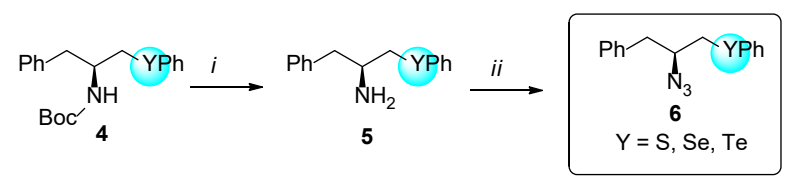

Scheme 2. Synthesis of chiral $\beta$-arylchalcogenium azides 6 (Miyashita et al. 1988) [a] Reagents and conditions: (i) TFA, $\mathrm{CH}_{2} \mathrm{Cl}_{2}$, rt; (ii) $\mathrm{NEt}_{3}, \mathrm{CuSO}_{4} \cdot 5 \mathrm{H}_{2} \mathrm{O}, \mathrm{CH}_{3} \mathrm{CN}, 3 \mathrm{~h}$. The final $\beta$-arylchalcogenium azide compounds are shown in Figure 1 (a) S601AZ (b) S602AZ $\quad$ (c) S603AZ and (d) S604AZ. All the compounds were diluted in dimethyl sulfoxide (DMSO). The other chemical reagents utilized were obtained from Sigma Chemical (St Louis, MO, USA).

\section{C. elegans strains and handling of the worms}

C. elegans Bristol N2 (wild type) and CF1553 [muls84] (SOD-3::GFP) were provided by the Caenorhabditis Genetics Center (CGC, Minnesota). Worms were kept in incubators at $20^{\circ} \mathrm{C}$ in petri dishes containing solid nematode growth medium and Escherichia coli OP50 as food source (Brenner 1974). The nematodes were exposed to treatments the first larval stage (L1), which are obtained by a synchronization process, in which eggs of pregnant hermaphrodites are obtained by using a solution of sodium hypochlorite (1\% NaOCl, $0.25 \mathrm{M} \mathrm{aOH}$ ) to break the cuticle of the worms. After 12-14 hours, the isolated eggs hatch and release the L1 larvae.

\section{Survival tests}

L1 worms were exposed to treatment with different concentrations of the compounds (1, $10,100,500$ and $1000 \mu \mathrm{M})$ for 30 minutes in a liquid medium containing $0.5 \% \mathrm{NaCl}$ and no food. At the end of the treatment, worms were washed three times with $0.5 \% \mathrm{NaCl}$ solution to remove all residues of the compounds and after placed on petri dishes containing NGM seeded with E. coli OP50. After 24 hours, alive animals were scored and a concentration-response curve was plotted. At least 4 independent experiments were performed.

\section{Oxidative stress-resistance}

After the last wash to remove the treatment with the compounds, worms were post-treated with the pro-oxidant hydrogen peroxide $\left(\mathrm{H}_{2} \mathrm{O}_{2}\right)$ $(1 \mathrm{mM})$ for $30 \mathrm{~min}$. Subsequently, nematodes were washed four more times, and then were placed on petri dishes containing NGM / OP50 medium. The number of surviving nematodes on each plate after $24 \mathrm{~h}$ post-exposure was scored to determine stress resistance (An \& Blackwell 2003). At least 4 independent experiments were performed.<smiles>N[C@@H](C[Se]c1ccccc1)Cc1ccccc1</smiles><smiles>N[C@@H](CSc1ccccc1)Cc1ccccc1</smiles>

Figure 1. Chemical structures of $\beta$-arylchalcogenium azide compounds (a) S601AZ (b) S602AZ (c) S603AZ and (d) S604AZ.<smiles>N[C@H](C[Te]c1ccccc1)Cc1ccccc1</smiles><smiles>Cc1ccccc1[Se]C[C@H](N)Cc1ccccc1</smiles> 


\section{SOD expression}

In order to find a mechanism by which the compounds would be protecting against $\mathrm{H}_{2} \mathrm{O}_{2}$, the concentration of $10 \mu \mathrm{M}$ was chosen for the next assay. CF1553 treated worms (as above described) were placed on recovery NGM/OP50 plates for $24 \mathrm{~h}$ and then transferred to slides containing levamisole (0.2\%) and M9 buffer and imaged in a FLoid Cell Imaging Station (Molecular Devices). The fluorescence was quantified using ImageJ software. At least 4 independent experiments were performed.

\section{Statistical Analysis}

All experiments were repeated at least 4 times in duplicates. Statistical analysis was carried out by one-way or two-way analysis of variance (to compare survival rate among compounds), followed by Tukey post-hoc test when $p<0.05$.

\section{RESULTS}

\section{$\beta$-aryl-chalcogenium azide compounds have low toxicity}

Figure 2 shows the survival curve of treated wild-type worms (N2), demonstrating that $\beta$-aryl-chalcogenium azide compounds decreased $C$. elegans survival only at the highest concentrations (500 and $1000 \mu \mathrm{M}$ ). Notably, a higher survival rate was found in worms exposed to S604AZ when compared to the others compounds.

\section{$\beta$-aryl-chalcogenium azide compounds reverse} the damage induced by hydrogen peroxide (H2O2) in C. elegans

Hydrogen peroxide $(0.4 \mathrm{mM})$ decreased the survival of wild-type worms (N2) when compared to control group. At the concentration of $1 \mu \mathrm{M}$, the pre-treatment with S601AZ, S602AZ and S603AZ did not protect against the mortality induced by hydrogen peroxide. Only the pre-treatment with $\mathrm{S} 604 \mathrm{AZ}$ presented a significant difference in relation to $\mathrm{H}_{2} \mathrm{O}_{2}$ group (Figure $3 \mathrm{a}$ ). Notably, the pre-treatment with all $\beta$-aryl-chalcogenium azide compounds at the concentration of 10 $\mu \mathrm{M}$ promoted a protection against the stress induced by hydrogen peroxide (Figure $3 b$ ).

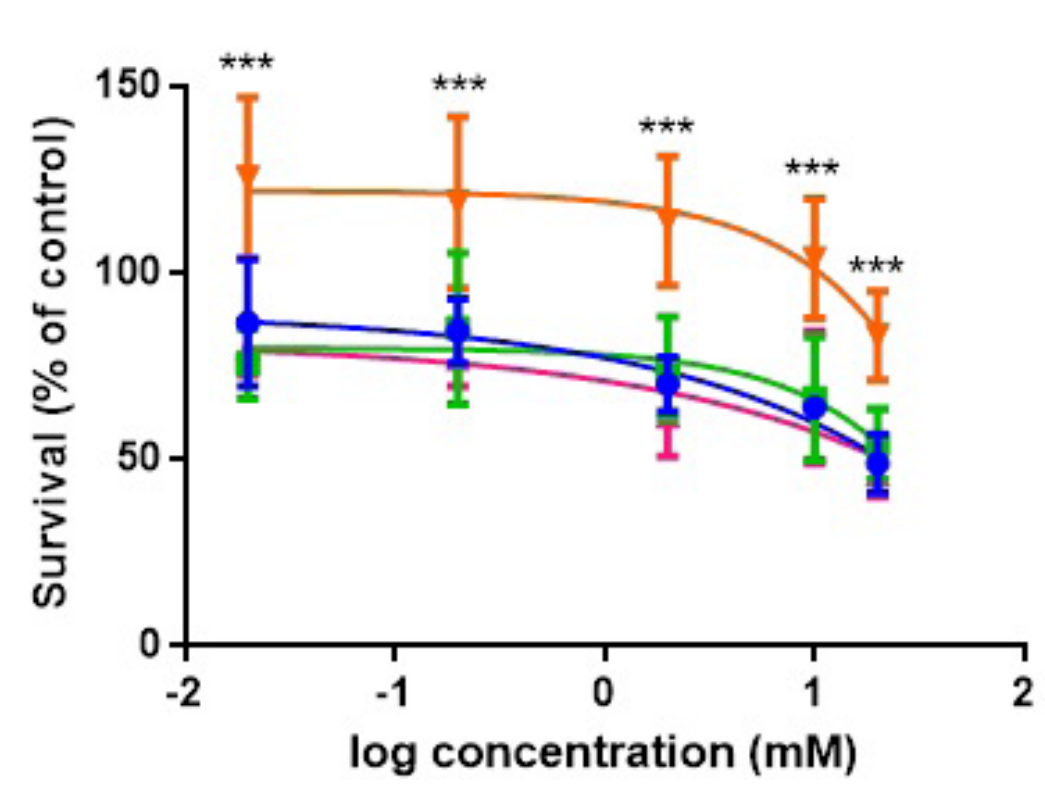

Figure 2. $\beta$-arylchalcogenium azide compounds have low toxicity in the survival of C. elegans. Data represent the mean \pm SEM of three to four experiments. ${ }^{* * *} p<0.001$ as compared to S601AZ, S602AZ, S603AZ groups. 

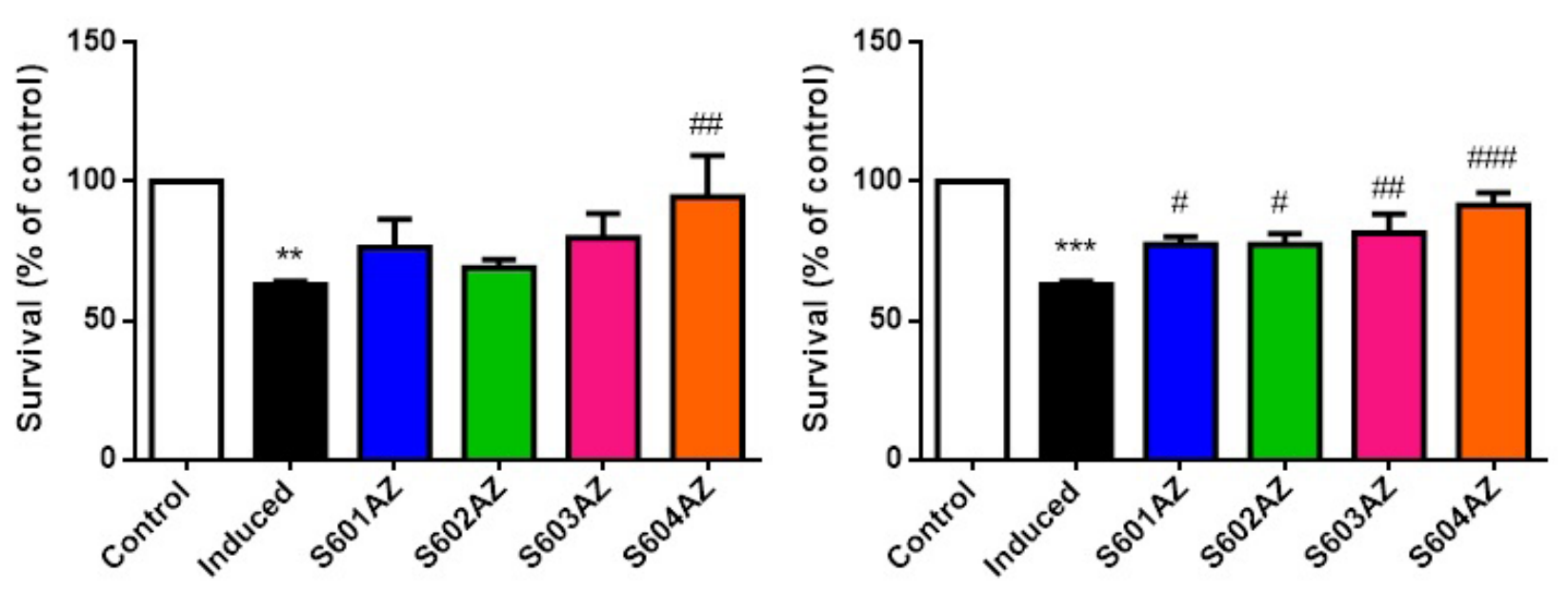

Figure 3. The effect of $\beta$-aryl-chalcogenium azide compounds at concentration of $1 \mu \mathrm{M}(\mathrm{a})$ and $10 \mu \mathrm{M}(\mathrm{b})$ against the damage induced by hydrogen peroxide $\left(\mathrm{H}_{2} \mathrm{O}_{2}\right)$ in C. elegans. Data represent the mean $\pm \mathrm{SEM}$ of three to four experiments. ${ }^{* *} p<0.01 ;{ }^{* * *} p<0.001$ as compared to control group, ${ }^{\#} p<0.05 ; " \# p<0.01 ; " \# p<0.001$ as compared to induced group.

\section{$\beta$-aryl-chalcogenium azide molecules modulate SOD-3 expression}

In order to find a mechanism by which the compounds would be protecting against $\mathrm{H}_{2} \mathrm{O}_{2}$, we analyzed superoxide dismutase enzyme expression, which was labeled with GFP. In figure 4 we demonstrate representative images of strain CF1553 that expresses superoxide dismutase isoform 3 in worms. Figure 5 shows the fluorescence quantification of CF1553 strain, in which the treatment with S601AZ, S602AZ did not change SOD expression. Remarkably, worms treated with $10 \mu \mathrm{M}$ of S603AZ and S604AZ showed a significant increase in SOD-3 expression.

\section{DISCUSSION}

In the present study, we examined the toxicity of a novel class of organochalcogen compounds using C. elegans as an experimental model. These $\beta$-aryl-chalcogenium azide compounds caused low toxicity to $C$. elegans and provided a stressresistance response action against hydrogen peroxide by modulating SOD-3 expression.
Many different classes of organotellurium and organoselenium compounds have been prepared and studied to date. In addition to their usefulness in the field of organic chemistry, the toxicological and pharmacological aspects of these compounds have also been recently investigated (Zeni \& Larock 2006). The organochalcogens present an atom of sulfur (S), selenium (Se) or tellurium (Te) in their chemical structure and have been considered promising pharmacological agents (Nogueira et al. 2004).

$S$ is a mineral that exerts important functions in our body and is directly related to essential metabolic functions. It is also required for the formation of the bones, hair nails and skin (Bin et al. 2017, Drewnoski et al. 2014). Se is an essential nutrient closely related to complex enzymatic and metabolic functions, and has been associated to the prevention of a wide variety of diseases (Duntas \& Benvenga 2015). Furthermore, Se is part of the several glutathione peroxidase isoforms and therefore essential for the antioxidant system (Duntas \& Benvenga 2015). 

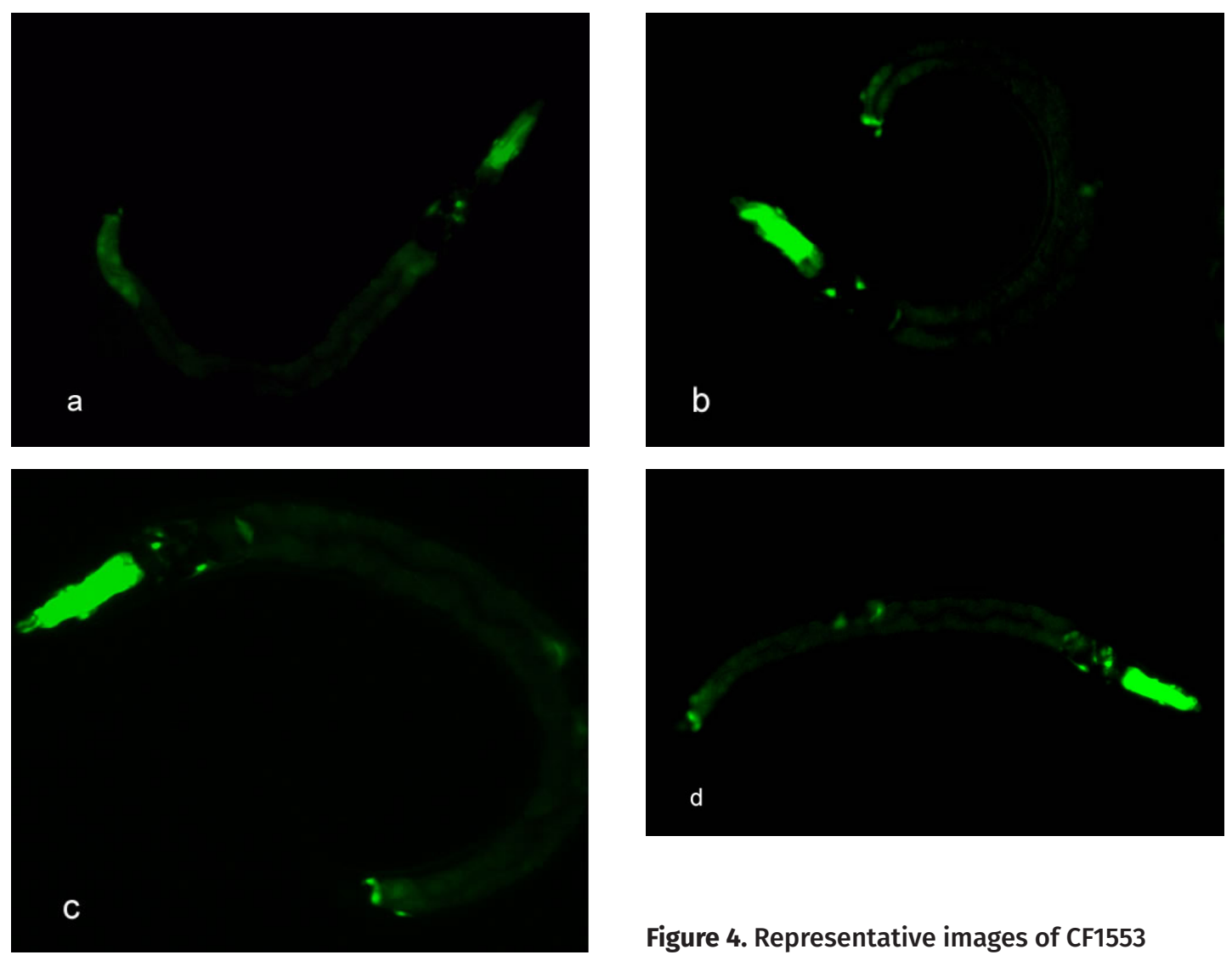

Figure 4. Representative images of CF1553 worms 24 hours after the treatment with the $\beta$-aryl-chalcogenium azide compounds at concentration of $10 \mu \mathrm{M}$ (a) Control (b) Compound S601AZ (c) Compound S602AZ (d) Compound S603AZ (e) Compound S604AZ. Data represent the mean \pm SEM of three to four experiments.

Different from $\mathrm{S}$ and Se, Te is not of great importance for biological functions in mammals, however many molecules containing this atom depict neuroprotective, hepatoprotective and anticancer properties (Chagas et al. 2017, Quines et al. 2014, Nogueira et al. 2004, Avila et al. 2012), which may be associated with their antioxidant activity in oxidative stress models (Tiekink 2012, Orian \& Toppo 2014). Based on that, we first investigated the toxicological potential of chalcogenoazides, and only at high concentrations, the compounds presented toxicity in C. elegans. Similar with our results, it has been demonstrated that the treatment with organoselenium and organotellurium compounds caused low toxicity in C. elegans (Avila et al. 2012, Soares et al. 2019). Notably, it was not possible to test concentrations above $1000 \mu \mathrm{M}$ due to the solubility of the compounds and therefore it was not possible to obtain sufficient information to calculate an $\mathrm{LC}_{50}$. 


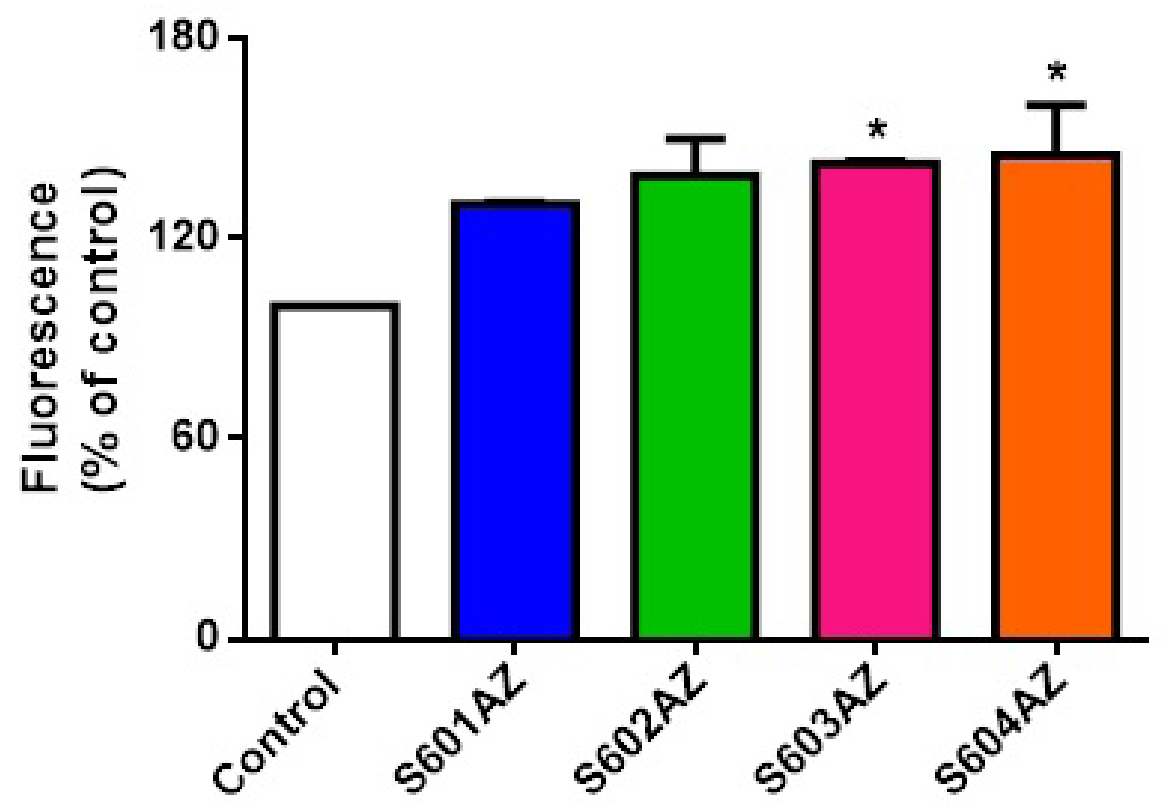

Figure 5. Fluorescence quantification of CF1553 animals treated with $\beta$-aryl-chalcogenium azide compounds at concentration of $10 \mu \mathrm{M}$. Data represent the mean \pm SEM of three to four experiments. ${ }^{*} p<0.05$ as compared to control.

However, it is important to note that the compound S603AZ, which contains tellurium in its composition, did not presented higher toxicity than the other compounds. This is an interesting result because $\mathrm{Te}$ is usually very toxic to different species when compared to $\mathrm{S}$ and Se analogues (Nogueira et al. 2004). This toxicity is usually related to the higher thiol oxidation ability of Te-containing molecules. For instance, diphenyl ditelluride inhibited $\mathrm{Na}^{+} / \mathrm{K}^{+}$ ATPase activity at lower concentrations that its analogue diphenyl diselenide, in vitro (Borges et al. 2005). On the other hand, several studies, including from our group, have evidenced that Te- containing molecules of low toxicity have great pharmacological potential (Salgueiro et al. 2017, Avila et al. 2012, Puntel et al. 2016). Notably, Tabarelli et al. (2017) demonstrated that chalcogenoazides (same class as the compounds studied here) that contain Te exhibited more prominent anti-tumoral activity and induced apoptosis in lung cancer cells. These molecules also depicted antioxidant activity and did not cause detectable toxicity in rats.
In addition, the compound S604AZ, which contains Se, an azide and an electron donor group (Me), depicted very low toxicity when compared to the other tested compounds. In this sense, we believe that besides the type of chalcogen, the toxicity of these compounds has been associated to the stability of the carbonchalcogen bond, which can be influenced by the ligands of the molecule (Nogueira et al. 2004). S604AZ presents a methyl group bound to the phenyl ring, which is an electron donor, thus leaving se more nucleophilic and facilitating the selenol generation. Selenol is one of the main form with the capacity of interacting with prooxidants and increasing the antioxidant defenses instead of causing toxic effects (Nogueira et al. 2004).

In order to verify the antioxidant activity of these organic molecules containing S, Se and Te in C. elegans, we performed the stressresistance test. Our results demonstrated that the pre-treatment with the chalcogenoazides caused a protection against the stress induced by $\mathrm{H}_{2} \mathrm{O}_{2}$ (responsible for generating hydroxyl radical) at the highest concentration used. In 
addition, at the concentration of $1 \mu \mathrm{M}$ S604AZ promoted significant protection against the damage induced by $\mathrm{H}_{2} \mathrm{O}_{2}$. This low dose can be explained by the fact that the therapeutic window of organochalcogen compounds is narrow (Meinerz et al. 2014, Caeran Bueno et al. 2013). The pharmacological and toxicological actions of these compounds share the same mechanisms, such as thiol oxidation and consequent alterations in the redox status of the cells (Rocha et al. 2017, Nogueira et al. 2004). Our group has evidenced that the expression of some genes can be differently induced by similar concentrations of these compounds (Salgueiro et al. 2017).

Selenols have great $\mathrm{H}_{2} \mathrm{O}_{2}$ scavenger potential. The oxidation of $\mathrm{H}_{2} \mathrm{O}_{2}$, represents the initial step of the antioxidant activity of glutathione peroxidase (GPX) and several organoselenium compounds are known for their GPx-like activity (Nogueira et al. 2004). For example, ebselen can react with thiols (e.g. glutathione (GSH)), yielding a selenenyl sulfide intermediate. After, the selenenyl sulfide reacts with another GSH molecule to yield selenol. The selenol reacts with $\mathrm{H}_{2} \mathrm{O}_{2}$ to form $\mathrm{H}_{2} \mathrm{O}$ or the respective alcohol $(\mathrm{ROH})$, resulting in ebselen selenenic acid intermediate, which spontaneously produces another molecule of $\mathrm{H}_{2} \mathrm{O}$ and regenerates ebselen (Nogueira et al. 2004). Regarding the Te compounds, Bortoli et al. (2017) suggest that Te derivatives are expected to react much more easily with $\mathrm{H}_{2} \mathrm{O}_{2}$, through a direct oxidation pathway, whereas their less efficient in GPx-like activity in relation to selenium compounds.

With the aim to investigate the possible mechanism of action of $\beta$-aryl-chalcogenium azides compounds, we analyzed the expression pattern of strain CF1553, which express the enzyme SOD-3 labeled with green fluorescent protein (GFP). We have observed an increase in the expression of SOD-3::GFP by the treatment with the compounds S603AZ and S604AZ, which present a Te and Se atom in their structure, respectively. One possible explanation is the DAF-16 translocation to the nucleus, increasing the SOD-3 expression, and then neutralizing the ROS generated in response to any xenobiotic, as evidenced with other organochalcogens (Wollenhaupt et al. 2014, Salgueiro et al. 2014). This finding is in agreement with previous studies of our group, in which xylofuranoside compounds that contain Se or Te induced the migration of DAF-16 to the nucleus, as well as increased expression of SOD-3 in the animals (Wollenhaupt et al. 2014).

Furthermore, previous studies also have reported an increase in mRNA and SOD-3::GFP expression in wild-type worms treated with 4-phenylchalcogenil-7-chloroquinolines. In fact, over-expression and/or overactivation of SOD-3 are required for the induction of pro-longevity response after mild oxidative injury (Salgueiro et al. 2017). In agreement with our results, it has been demonstrated that the treatment with organochalcogen compounds present an antioxidant action in the liver of rats by increasing the activity of SOD-3 and decreasing the generation of reactive species in different disease models (Quines et al. 2017, Sartori et al. 2017).

\section{CONCLUSION}

In summary, the presented study showed that the $\beta$-aryl-chalcogenium azide compounds caused low toxicity to $C$. elegans and demonstrated a stress-resistance response action against peroxide hydrogen by modulating SOD-3 expression.

\section{Acknowledgments}

Authors acknowledge funding from Conselho Nacional de Desenvolvimento Científico e Tecnológico (CNPq 
-Universal Grants), Fundação de Amparo à Pesquisa no Estado do Rio Grande do Sul (FAPERGS / PRONEM- Rede Gaúcha de Métodos Alternativos) and Universidade Federal do Pampa (UNIPAMPA). D.S.A and O.E.D are recipients of researcher fellowship (CNPq).

\section{REFERENCES}

AN JH \& BLACKWELL TK. 2003. SKN-1 links C. elegans mesendodermal specification to a conserved oxidative stress response. Genes \& Development 17: 1882-1893.

ANDREADOU I, MENGE WM, COMMANDEUR JN, WORTHINGTON EA \& VERMEULEN NP. 1996. Synthesis of novel Se-substituted selenocysteine derivatives as potential kidney selective prodrugs of biologically active selenol compounds: evaluation of kinetics of $\beta$-elimination reactions in rat renal cytosol. J Med Chem 39: 2040-2046.

AVILA DS, BENEDETTO A, AU C, MANARIN F, ERIKSON K, SOARES FA, ROCHA JB \& ASCHNER M. 2012. Organotellurium and organoselenium compounds attenuate $\mathrm{Mn}$-induced toxicity in Caenorhabditis elegans by preventing oxidative stress. Free Radic Biol Med 52: 1903-1910.

AZADMANESH J \& BORGSTAHL GEO. 2018. A Review of the Catalytic Mechanism of Human Manganese Superoxide Dismutase. Antioxidants 7.

BIN P, HUANG R \& ZHOU X. 2017. Oxidation Resistance of the Sulfur Amino Acids: Methionine and Cysteine. Biomed Res Int 2017: 9584932.

BONETTA R. 2018. Potential Therapeutic Applications of MnSODs and SOD-Mimetics. Chemistry 24(20): 5032-5041.

BORGES VC, ROCHA JB \& NOGUEIRA CW. 2005. Effect of diphenyl diselenide, diphenyl ditelluride and ebselen on cerebral $\mathrm{Na}(+), \mathrm{K}(+)$-ATPase activity in rats. Toxicology 215: 191-197.

BORTOLI M, TORSELLO M, BICKELHAUPT FM \& ORIAN L. 2017. Role of the Chalcogen ( $\mathrm{S}, \mathrm{Se}, \mathrm{Te}$ ) in the Oxidation Mechanism of the Glutathione Peroxidase Active Site. Chemphyschem: a European Journal of Chemical Physics and Physical Chemistry 18: 2990-2998.

BRENNER S. 1974. The genetics of Caenorhabditis elegans. Genetics 77: 71-94.

CAERAN BUENO D, MEINERZ DF, ALLEBRANDT J, WACZUK EP, DOS SANTOS DB, MARIANO DO \& ROCHA JB. 2013. Cytotoxicity and genotoxicity evaluation of organochalcogens in human leucocytes: a comparative study between ebselen, diphenyl diselenide, and diphenyl ditelluride. Biomed Res Int 2013: 537279.
CHAGAS PM, FULCO BCW, SARI MHM, ROEHRS JA \& NOGUEIRA CW. 2017. Bis(phenylimidazoselenazolyl) diselenide elicits antinociceptive effect by modulating myeloperoxidase activity, NOx and NFKB levels in the collagen-induced arthritis mouse model. J Pharm Pharmacol 69(8): 1022-1032.

DREWNOSKI ME, POGGE DJ \& HANSEN SL. 2014. High-sulfur in beef cattle diets: a review. J Anim Sci 92: 3763-3780.

DUNTAS LH \& BENVENGA S. 2015. Selenium: an element for life. Endocrine 48: 756-775.

GOODMAN MA \& DETTY MR. 2004. Selenoxides as catalysts for the activation of hydrogen peroxide. Bromination of organic substrates with sodium bromide and hydrogen peroxide. Organometallics 23: 3016-3020.

GRAY EG \& WHITTAKER VP. 1962. The isolation of nerve endings from brain: an electron-microscopic study of cell fragments derived by homogenization and centrifugation. J Anat 96: 79-88.

MEINERZ DF, ALLEBRANDT J, MARIANO DO, WACZUK EP, SOARES FA, HASSAN W \& ROCHA JB. 2014. Differential genotoxicity of diphenyl diselenide (PhSe)2 and diphenyl ditelluride (PhTe)2. PeerJ 2: e290.

MIYASHITA M, HOSHINO M \& YOSHIKOSHI A. 1988. Sodium phenylseleno (triethoxy) borate, $\mathrm{Na}+$ (PhSeB (OEt) 3]-: The reactive species generated from (PhSe) 2 with $\mathrm{NaBH} 4$ in ethanol. Tetrahedron Lett 29: 347-350.

NOGUEIRA CW, ZENI G \& ROCHA JB. 2004. Organoselenium and organotellurium compounds: toxicology and pharmacology. Chem Rev 104: 6255-6285.

ORIAN L \& TOPPO S. 2014. Organochalcogen peroxidase mimetics as potential drugs: a long story of a promise still unfulfilled. Free Radic Biol Med 66: 65-74.

POPRAC P, JOMOVA K, SIMUNKOVA M, KOLLAR V, RHODES CJ \& VALKO M. 2017. Targeting Free Radicals in Oxidative Stress-Related Human Diseases. Trends Pharmacol Sci 38: 592-607.

PUNTEL RL, AVILA DS, ROOS DH \& PINTON S. 2016. Mitochondrial Effects of Organoselenium and Organotellurium Compounds. Curr Org Chem 20: 198-210.

QUINES CB, CHAGAS PM, HARTMANN D, CARVALHO NR, SOARES FA \& NOGUEIRA CW. 2017. ( $p$-ClPhSe)2 Reduces Hepatotoxicity Induced by Monosodium Glutamate by Improving Mitochondrial Function in Rats. J Cell Biochem 118(9): 2877-2886.

QUINES CB, ROSA SG, DA ROCHA JT, GAI BM, BORTOLATTO CF, DUARTE MMMF \& NOGUEIRA CW. 2014. Monosodium glutamate, a food additive, induces depressive-like and 
anxiogenic-like behaviors in young Rats. Life Sci 107: 27-31.

ROCHA JB, PICCOLI BC \& OLIVEIRA CS. 2017. Biological and chemical interest in selenium: a brief historical account. ARKIVOC: Online J Org Chem, p. 457-491.

SALGUEIRO WG, GOLDANI BS, PERES TV, MIRANDA-VIZUETE A, ASCHNER M, DA ROCHA JBT, ALVES D \& AVILA DS. 2017. Insights into the differential toxicological and antioxidant effects of 4-phenylchalcogenil-7-chloroquinolines in Caenorhabditis elegans. Free Radic Biol Med 110: 133-141.

SALGUEIRO WG, XAVIER MC, DUARTE LF, CAMARA DF, FAGUNDEZ DA, SOARES AT, PERIN G, ALVES D \& AVILA DS. 2014. Direct synthesis of 4-organylsulfenyl-7-chloro quinolines and their toxicological and pharmacological activities in Caenorhabditis elegans. Eur J Med Chem 75: 448-459.

SARTORI G, JARDIM NS, SARI MH, FLORES EF, PRIGOL M \& NOGUEIRA CW. 2017. Diphenyl Diselenide Reduces Oxidative Stress and Toxicity Caused by HSV-2 Infection in Mice. J Cell Biochem 118: 1028-1037.

SOARES ATG, JUNIOR LBLR, SALGUEIRO WG, DAL FORNO AHDC, RODRIGUES CF, SACRAMENTO M, FRANCO J, ALVES D, DE PAULA OLIVEIRA R \& PINTON S. 2019. Organoselenotriazoles attenuate oxidative damage induced by mitochondrial dysfunction in mev-1 Caenorhabditis elegans mutants. J Trace Elem Med Biol 53: 34-40.

TABARELLI G ET AL. 2017. Synthesis and Antitumoral Lung Carcinoma A549 and Antioxidant Activity Assays Of New Chiral $\beta$-Aryl-Chalcogenium Azide Compounds. ChemistrySelect 2: 8423-8430.

TIEKINK ER. 2012. Therapeutic potential of selenium and tellurium compounds: opportunities yet unrealised. Dalton Trans 41: 6390-6395.

WOLLENHAUPT SG ET AL. 2014. Seleno- and telluroxylofuranosides attenuate $\mathrm{Mn}$-induced toxicity in C. elegans via the DAF-16/FOXO pathway. Food and chemical toxicology: an international journal published for the British Industrial Biological Research Association 64: 192-199.

XIONG Z, HONGMEI Z, LU S \& YU L. 2011. Curcumin mediates presenilin-1 activity to reduce beta-amyloid production in a model of Alzheimer's Disease. Pharmacol Rep: PR 63: 1101-1108.

YAN R-B, YANG F, WU Y, ZHANG L-H \& YE X-S. 2005. An efficient and improved procedure for preparation of triflyl azide and application in catalytic diazotransfer reaction. Tetrahedron Lett 46: 8993-8995.
ZENI G \& LAROCK RC. 2006. Synthesis of heterocycles via palladium-catalyzed oxidative addition. Chem Rev 106: 4644-4680.

\section{How to cite}

MOTTA HS, ROOS D, TABARELLI G, RODRIGUES OED, ÁVIAL D \& QUINES CB. 2020. Activation of SOD-3 is involved in the antioxidant effect of a new class of $\beta$-aryl-chalcogenium azide compounds in Caenorhabditis elegans. An Acad Bras Cienc 92: e20181147. DOI 10.1590/00013765202020181147.

Manuscript received on October 31, 2018;

accepted for publication on april 8, 2019

HODARA S. MOTTA ${ }^{1}$

https://orcid.org/0000-0003-1818-7179

\section{DANIEL ROOS}

https://orcid.org/0000-0002-3413-8863

\section{GREICE TABARELLI ${ }^{2}$}

https://orcid.org/0000-0001-9799-1979

\section{OSCAR E.D. RODRIGUES}

https://orcid.org/0000-0003-4382-1637

\section{DAIANA ÁVILA}

https://orcid.org/0000-0002-8673-1909

\section{CAROLINE B. QUINES 1}

https://orcid.org/0000-0002-3818-1690

${ }^{1}$ Universidade Federal do Pampa, Laboratório de Bioquímica e Toxicologia em Caenorhabditis elegans, BR 472, Km 585, Caixa Postal 118, 97501-970 Uruguaiana, RS, Brazil

${ }^{2}$ Universidade Federal de Santa Maria, Avenida Roraima, 1000, Cidade Universitária, Camobi, 97105-900 Santa Maria, RS, Brazil

Correspondence to: Caroline Brandão Quines

E-mail:carolinequines@alunos.unipampa.edu.br

\section{Author contributions}

Hodara Santos Motta and Caroline Brandão Quines: Experiments execution and manuscript writing. Daniel Roos: Study conceptualization and manuscript revision. Greice Tabarelli and Oscar Endrigo Dorneles Rodrigues: Compounds synthesis and manuscript writing. Daiana Ávila: Study conceptualization and manuscript revision.

\section{(c) $B \mathrm{BY}$}

